\title{
Solid Modeling and Finite Element Analysis of an Overhead Crane Bridge
}

\author{
C. Alkin, C. E. Imrak, H. Kocabas
}

The design of an overhead crane bridge with a double box girder has been investigated and a case study of a crane with 35 ton capacity and $13 \mathrm{~m}$ span length has been conducted. In the initial phase of the case study, conventional design calculations proposed by $F$. E. M Rules and DIN standards were performed to verify the stress and deflection levels. The crane design was modeled using both solids and surfaces. Finite element meshes with 4-node tetrahedral and 4-node quadrilateral shell elements were generated from the solid and shell models, respectively. After a comparison of the finite element analyses, the conventional calculations and performance of the existing crane, the analysis with quadratic shell elements was found to give the most realistic results. As a result of this study, a design optimization method for an overhead crane is proposed.

Keywords: overhead crane, finite element method, solid modeling, box girder.

\section{Notation}

$b \quad$ distance between two side plates

$b_{\mathrm{k}} \quad$ width of lower plate

$F_{\mathrm{AA}} \quad$ static load due to the trolley

$F_{\mathrm{Y}} \quad$ load due to the working load

$h_{0} \quad$ height of the girder end

$h_{2} \quad$ height of the side plates

$L_{\mathrm{A}} \quad$ distance between trolley wheels

$L_{\mathrm{K}} \quad$ span of crane girder

$L_{\mathrm{P}} \quad$ distance between two adjacent supports

$q \quad$ weight of one meter platform

$q_{\mathrm{K}} \quad$ weight of one meter maintenance platform

$q_{\mathrm{P}} \quad$ uniformly distributed mass units of bridge

$t_{1} \quad$ thickness of the upper and lower plates

$t_{2} \quad$ thickness of the side plates

$x_{2} \quad$ distance between center of gravity and the midpoint of the left side plate

$x_{4} \quad$ distance between center of gravitiy and the midpoint of the rail

$y_{1} \quad$ distance between neutral axis and the midpoint of the rail

distance between center of gravity and the midpoint of the top plate

$y_{5}$ distance between neutral axis and the midpoint of the top plate

$W_{\mathrm{X} 1} \quad$ moment of resistance on $\mathrm{x}$-axis

$W_{\mathrm{Y} 1}$ moment of resistance on y-axis

$\gamma_{\mathrm{C}} \quad$ amplifying coefficient

$\psi \quad$ dynamic coefficient

\section{Introduction}

Cranes are the best way of providing a heavy lifting facility covering virtually the whole area of a building. An overhead crane is the most important materials handling system for heavy goods. The primary task of the overhead crane is to handle and transfer heavy payloads from one position to another. Thus they are used in areas such as automobile plants and shipyards $[1,2]$. Their design features vary widely according to their major operational specifications, such as: type of motion of the crane structure, weight and type of the load, location of the crane, geometric features and environmental conditions. Since the crane design procedures are highly standardized with these components, most effort and time are spent on interpreting and implementing the avaliable design standards [3].

There are many published studies on structural and component stresses, safety under static loading and dynamic behaviour of cranes [5-16]. Solid modeling of bridge structures and finite element analysis to find the displacements and stress values has been investigated by Demirsoy [17]. Solid modeling techniques applied for road bridge structures, and an analysis of these structures using the finite element method are provided in [18]. In this study, stress and displacements were found using FEM90 software. Solid modeling of a crane bridge, the loading at different points on the bridge and then application of the finite element method have been studied by Celiktas [19]. She presented the results of finite element methods for an overhead crane.

DIN-Taschenbuch and F. E. M. (Federation Européenne de la Manutention) Rules offer design methods and empirical approaches and equations that are based on previous design experience and widely accepted design procedures. DIN-Taschenbuch 44 and 185 are a collection of standards related to crane design. DIN norms generally state standard values of design parameters. F. E. M Rules are mainly an accepted collection of rules to guide crane designers. It includes criteria for deciding on the external loads to select crane components $[3,20]$.

In this study, the calculations apply the F. E. M. rules and DIN standards, which are used for box girder crane bridges. The calculation of the box girder uses the CESAN Inc. standard bridge tables. Then a solid model of the crane bridge is generated with the same dimensions as in the calculation results. Then static analysis is performed, using the Finite Element Method. Before starting the solution, the boundary conditions are applied as in practice.

\section{Overhead cranes with a double box girder}

Overhead travelling cranes with a double box girder not only hoist loads but also carry them horizontally. A double beam overhead crane is built of a trolley travelling on bridges, 


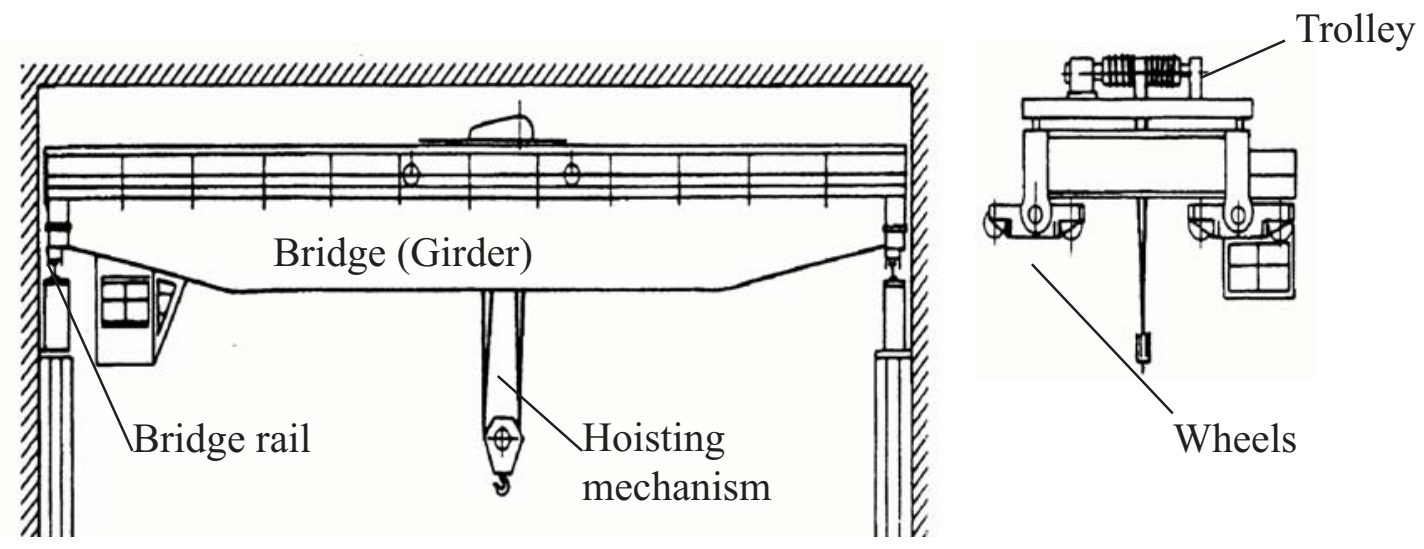

Fig. 1: Overall view of an overhead crane
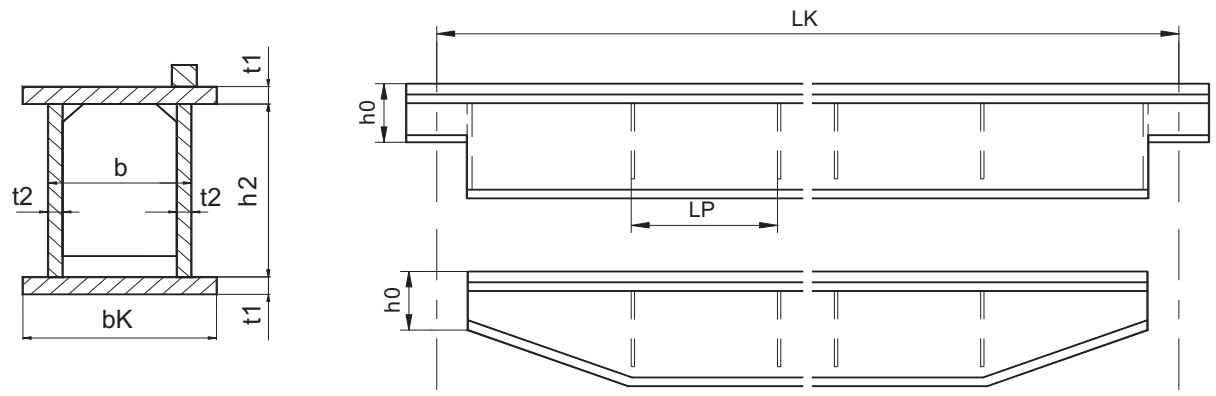

Fig. 2: Construction requirements for a box girder bridge

and bridges travelling on rails. The trolley hoists or lowers the loads and carries them on the bridge structure. The bridges carry the loads on a rail. As a result, three perpendicular movements are performed. The system is depicted in Fig. 1, where the payload of the mass is attached to the bridge with wire ropes [21, 22].

The double box girders are subjected to vertical and horizontal loads by the weight of the crane, the working (hook) load and the dynamic loads. With a double box girder construction, the trolley runs above or between the girders. The acceptable construction requirements and values for a box girder bridge structure are shown in Fig. 2.

\section{Application of FEM to an overhead crane}

Among numerical techniques, the finite element method is widely used due to the availability of many user-friendly commercial softwares. The finite element method can analyse any geometry, and solves both stresses and displacements [23]. FEM approximates the solution of the entire domain under study as an assemblage of discrete finite elements interconnected at nodal points on the element boundaries. The approximate solution is formulated over each element matrix and thereafter assembled to obtain the stiffness matrix, and displacement and force vectors of the entire domain. In this study finite element modeling is carried out by means of the Cosmosworks and MSC commercial package. Patran and 4-node tetrahedral elements and 4-node quadrilateral shell elements have been used for modeling the overhead crane bridge.
The four-node tetrahedral element is the simplest three-dimensional element used in the analysis of solid mechanics problems such as bracket stress analysis. This element has four nodes, with each node having three translational and three rotational degrees of freedom on the $x, y$, and $z$-axes. A shell element may be defined, which allows in the plane or curved surface of the element and posseses both length. It width and may only be used in 3-D simulations. The four-node shell element is obtained by assembling the bending element to the appropriate degrees of freedom. This is sufficient as long as the shell element deflection is within the predefined ratio of shell thickness, otherwise the system works as a large deflection.

A typical four-node tetrahedral element and four-node quadratic shell element, and their coordinate systems are illustrated in Fig. 3 [24]. The four-node tetrahedral element chosen has six degrees of freedom at each node: translation in the nodal $x, y$, and $z$ directions and rotations about the nodal $x, y$, and $z$ directions. For the four-node quadratic shell element used to model the overhead crane girder, $r$ and $s$ denote the natural coordinates and $\delta$ is the thickness of the element.

This system does not have any horizontal force. The axial displacements and rotations of the first and last faces are equal to zero. In addition, the transverse displacement is zero at the first and last face nodes.

The external forces acting on the system are the mass of the main girder of the crane (distributed load) and the forces acting on the wheels of the trolley along the crane (active load). The forces acting on the trolley wheels are caused by the mass of the trolley, an the lifting load which will be moved on the crane. 




4-node tetrahedral element

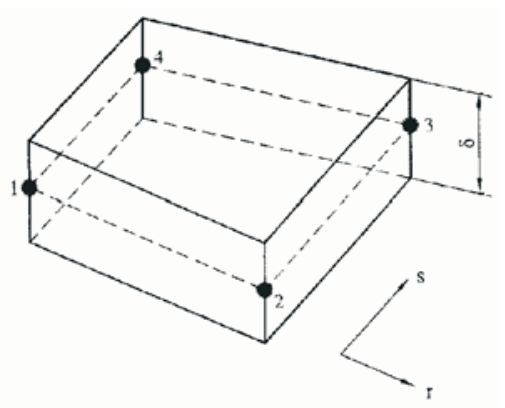

4-node quadratic shell element

Fig. 3: Elements used to model an overhead crane girder

\section{Solid and finite element modelling of an overhead crane bridge}

The finite element method is a numerical procedure that can be applied to obtain solutions to a variety of problems in engineering. Steady, transient, linear or nonlinear problems in stress analysis, heat transfer, fluid flow and electromechanism problems may be analysed with finite element methods. The basic steps in the finite element method are defined as follows: preprocessing phase, solution phase, and postprocessing phase.

Real crane data was gathered from CESAN Inc., a Turkish company involved in mass production of overhead cranes. First, the crane bridge is modeled as a surface. Bridge geometry is suitable for this, and long and thin parts should also be modeled as a surface. Later, a mesh is created. In this study, a quadratic element type is used. Solid modeling is generated for the calculated crane bridge and the solid model is shown in Fig. 4 [20].

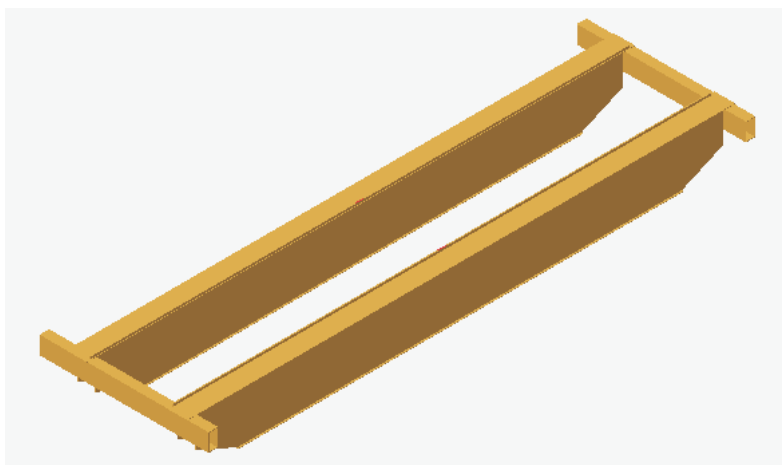

Solid model of a crane bridge

Fig. 4: Models of an overhead crane bridge

\section{Numerical example of an overhead crane}

A 35-ton-capacity overhead crane of overall length $13 \mathrm{~m}$ and total weight 22.5 tons was selected as a study object. The configuration of the overhead crane is shown in Fig. 1. The overhead crane consists of two girders, two saddles to connect them, and a trolley moving in the longitudinal direction of the overhead crane and wheels. The driving unit is installed in one of the two girders. The overhead crane is supported by two rails and the runway girders installed in building.

In order to calculate the stress in the structure, the rules of F. E. M 1.001 are applied. The design values used in the bridge analysis from the F. E. M and DIN standards are given in Table 1.

Table 1: Bridge property values

\begin{tabular}{|l|l|}
\hline Handling Capacity & $: G_{\mathrm{y}}=35$ ton \\
\hline Trolley Weight & $: F_{\mathrm{A}}=3$ ton \\
\hline Bridge Length & $: L_{\mathrm{K}}=13 \mathrm{~m}$ \\
\hline $\begin{array}{l}\text { Distance between wheels of } \\
\text { trolley }\end{array}$ & $: L_{\mathrm{A}}=2 \mathrm{~m}$ \\
\hline Trolley Velocity & $: V_{\mathrm{A}}=20 \mathrm{~m} / \mathrm{min}$. \\
\hline Crane Velocity & $: V_{\mathrm{F}}=15 \mathrm{~m} / \mathrm{min}$. \\
\hline Hoisting Velocity & $: V_{\mathrm{H}}=2.7 \mathrm{~m} / \mathrm{min}$ \\
\hline Total duration of use & $: \mathrm{U} 4$ \\
\hline Load spectrum class & $: \mathrm{Q} 3$ \\
\hline Appliance group & $: \mathrm{A} 5$ \\
\hline Loading type & $: \mathrm{H}(\mathrm{main}$ load) \\
\hline Dynamic coefficient & $: \psi=1.15$ \\
\hline Amplifying coefficient & $: \gamma_{\mathrm{C}}=1.11$ \\
\hline
\end{tabular}

First the maximum and minimum stresses and then the shear stress are calculated using the F. E. M. rules. Using the finite element method for the considered girder, we obtain the stress valnes. We obtain the static loads due to the dead weight, the loads due to the working load multiplied by the

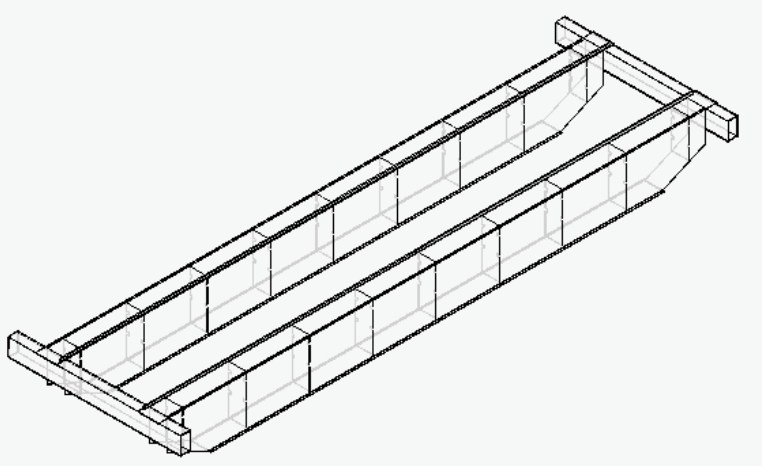

Wireframe view of a crane bridge 
dynamic coefficient, and the two most unfavourable horizontal effects, excluding the buffer forces.

The maximum stress consists of the stress on the bridge dead weights, the stress on the trolley dead weight, the stress from the hoisting load, stress from the inertia forces and the stress of the trolley contraction. The minimum stress includes the stress on the bridge dead weights and the stress on the trolley dead weight. The maximum and minimum stresses for the given values according to the F. E. M. rules [20] are written in standard form as

$$
\begin{aligned}
\sigma_{\max }=\gamma_{\mathrm{c}}\{ & \frac{\left(q_{\mathrm{K}}+q_{\mathrm{P}}\right) g \cdot L_{\mathrm{K}}^{2}}{8 W_{\mathrm{X} 1}}+\frac{F_{\mathrm{AA}}}{32 L_{\mathrm{K}} \cdot W_{\mathrm{X} 1}}\left(2 L_{\mathrm{K}}-L_{\mathrm{A}}\right)^{2} \\
& +\psi \frac{F_{\mathrm{Y}}}{32 W_{\mathrm{X} 1} \cdot L_{\mathrm{K}}}\left(2 L_{\mathrm{K}}-L_{\mathrm{A}}\right)^{2} \\
& +\frac{0.075 L_{\mathrm{K}}}{W_{\mathrm{Y} 1}}\left[\left(q_{\mathrm{K}}+q_{\mathrm{P}}\right) g \cdot L_{\mathrm{K}}+\frac{F_{\mathrm{AA}}}{2}\right] \\
& \left.+\frac{0.05 L_{\mathrm{A}}}{W_{\mathrm{Y} 1}}\left(F_{\mathrm{AA}}+F_{\mathrm{Y}}\right)\right\}
\end{aligned}
$$

and,

$\sigma_{\text {min }}=\gamma_{\mathrm{c}}\left[\frac{\left(q_{\mathrm{K}}+q_{\mathrm{P}}\right) g \cdot L_{\mathrm{K}}^{2}}{8 W_{\mathrm{X} 1}}+\frac{F_{\mathrm{AA}}}{32 L_{\mathrm{K}} \cdot W_{\mathrm{X} 1}}\left(2 L_{\mathrm{K}}-L_{\mathrm{A}}\right)^{2}\right]$.
The value of the dynamic coefficient $\psi$ is applied to the loading arising from the working load. The value of the amplifying coefficient $\gamma_{c}$ depends the group classification of the application, and the weight of one meter maintenance platform is zero in this work. [25].

It is assumed that the total load $(372780 \mathrm{~N})$ is effected on the mid point of the rail and each girder shares this total load equally. This load is applied via the contact points of the two trolley wheels in this system. Therefore the value of the acting force on each point is $93195 \mathrm{~N}$. Applying the total load in the system, the value of the maximum stress according to Eq. (1) is $143.90 \mathrm{~N} / \mathrm{mm}^{2}$ to two decimal places, and the value of the minimum stress according to Eq. (2) is $47.33 \mathrm{~N} / \mathrm{mm}^{2}$ to two decimal places.

According to Fig. 5, the permissible stress in shear consists of the shear stresses of the wheel forces, and is defined as [20]

$\tau=\frac{\left(x_{4}+0.2 y_{5}\right) \cdot\left(F_{\mathrm{AA}}+F_{\mathrm{Y}}\right)}{4 t_{2}\left(x_{2}+x_{4}\right) \cdot\left(y_{1}+y_{3}\right)}+\frac{\psi \cdot F_{\mathrm{Y}}+\gamma_{\mathrm{c}} \cdot F_{\mathrm{AA}}}{4 t_{2} \cdot h_{2}}$.

The value of the maximum shear stress is $24.82 \mathrm{~N} / \mathrm{mm}^{2}$ to two decimal places from Eq. (5). Substituting Eq. (1)-(3) the equivalent stress is given by. The value of the equivalent stress is $150.18 \mathrm{~N} / \mathrm{mm}^{2}$ to two decimal places.
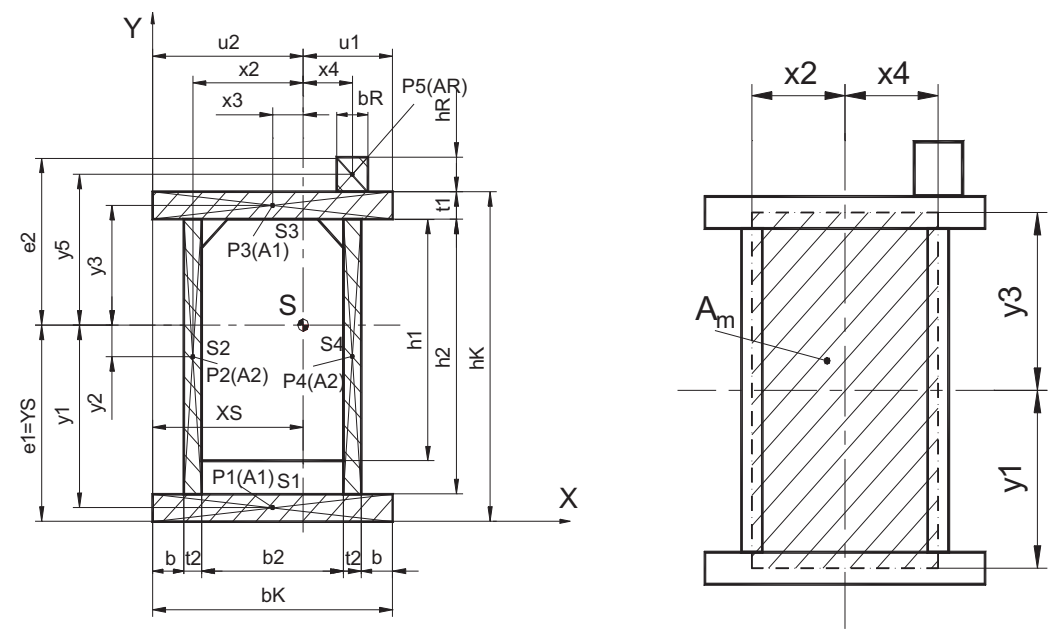

Fig. 5: Inertia and moment of resistance in a box girder

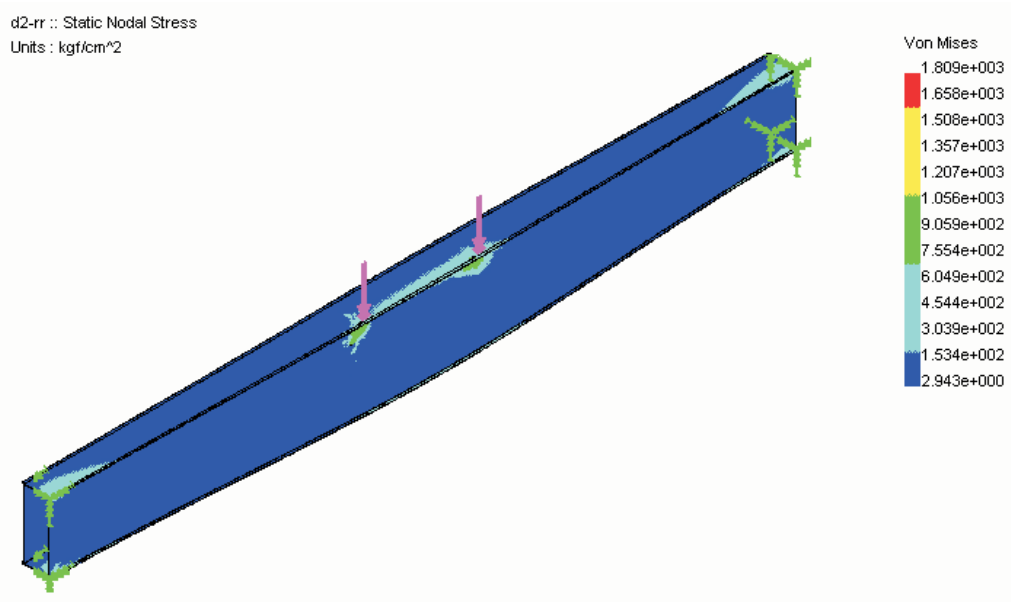

Fig. 6: Stress values of an overhead crane girder with a four-node tetrahedral element 


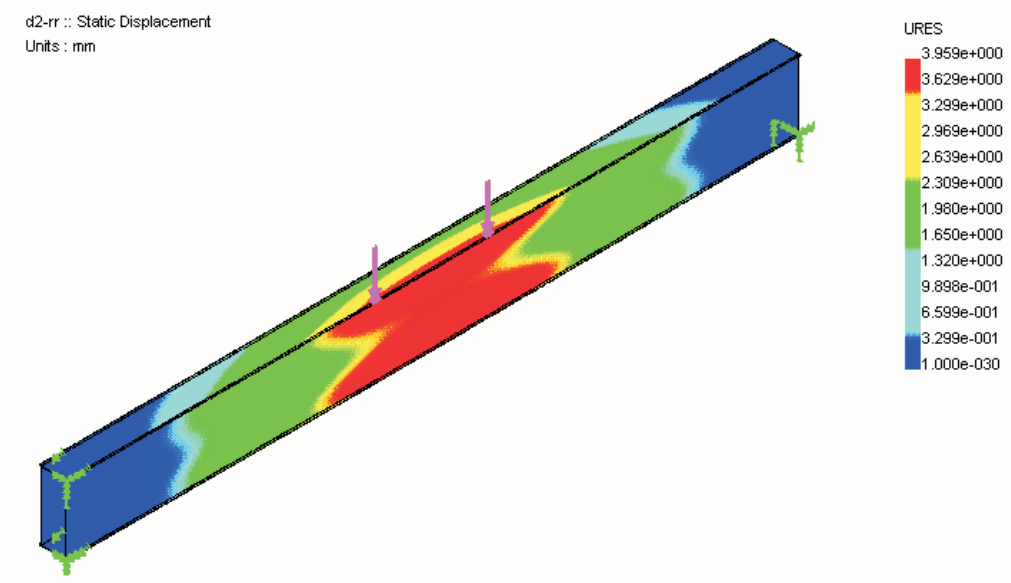

Fig. 7: Displacements of an overhead crane girder with a four-node tetrahedral element

\section{Results from a girder model with a four-node tetrahedral element}

To model the overhead crane girder with a four-node tethrahedral element, Cosmosworks software was used for finite element analysis using the girder solid model generated by means of SolidWorks 2003. Young's Modulus (E) is $2.1 \times 105 \mathrm{~N} / \mathrm{mm}^{2}$ and the Poisson Ratio $\left(v_{\mathrm{St}}\right)$ is 0.3 for finite element analysis. The value of the maximum stress of the side plate is $12.07 \mathrm{~N} / \mathrm{mm}^{2}$ to two decimal places and the value of the maximum stress of the bottom plate is $15.08 \mathrm{~N} / \mathrm{mm}^{2}$ to two decimal places from Fig. 6 [20].

The displacement of the modelled overhead crane girder was obtanied from CosmosWorks, and is illustrated in Fig. 7. The value of maximum displacement of the girder is about $2.2 \mathrm{~mm}$.

\section{Results from a girder model with a four-node quadratic shell element}

To model the overhead crane girder with a four-node quadratic shell element, MSC Patran software was used for the finite element analysis. Young's Modulus (E) is $2.1 \times 10 \mathrm{~N} / \mathrm{mm}^{2}$ and the Poisson Ratio $\left(v_{\mathrm{St}}\right)$ is 0.3 for finite element analysis. The value of the maximum stress of the side plate is $35.40 \mathrm{~N} / \mathrm{mm}^{2}$ to two decimal places, and the value of

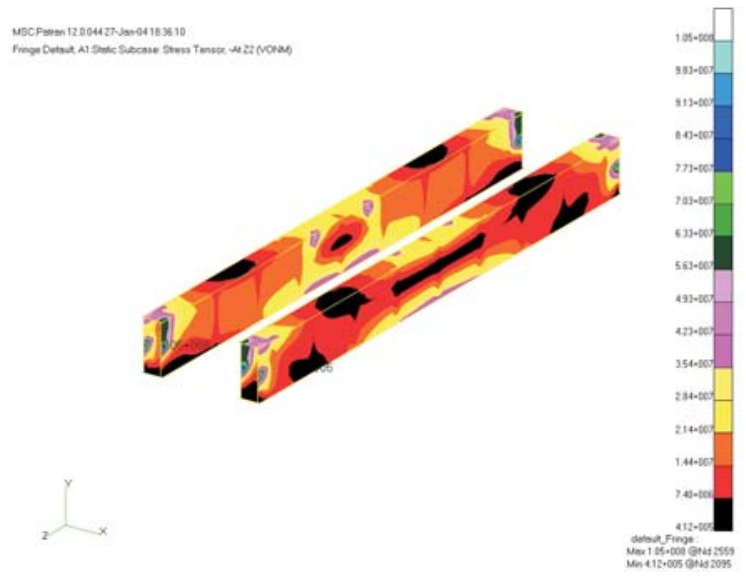

the maximum stress of the bottom plate is $49.30 \mathrm{~N} / \mathrm{mm}^{2}$ to two decimal places, from Fig. 8 [20].

The displacement of the modelled overhead crane girder was obtained from MSC Patran, and is illustrated in Fig. 9. The value of maximum displacement of the girder is about $3.89 \mathrm{~mm}$.

The value of the maximum stress according to Eq. (1) is calculated as $143.90 \mathrm{~N} / \mathrm{mm}^{2}$ to two decimal places. The safety factor should be considered between 2 and 3 for overhead crane girder design. The maximum stress value of the side plate is between 24.14 and $36.21 \mathrm{~N} / \mathrm{mm}^{2}$ to two decimal places, and the maximum stress value of the bottom plate is between 30.16 and $45.24 \mathrm{~N} / \mathrm{mm}^{2}$ to two decimal places for a four-node tetrahedral element, taking into account the safety factor.

The maximum stress value of the side plate is between 70.8 and $106.2 \mathrm{~N} / \mathrm{mm}^{2}$ to two decimal places and the maximum stress value of the bottom plate is between 98.6 and $147.9 \mathrm{~N} / \mathrm{mm}^{2}$ to two decimal places for a four-node quadratic shell element, taking into account the safety factor.

The permissible displacement of the girder is $13 \mathrm{~mm}$ according to F. E. M. rules. The maximum displacement obtained from the finite element model with a four-node tetrahedral element is between 4.40 and $6.60 \mathrm{~mm}$, taking into account the safety factor. The maximum displacement obtained from the finite element model with a four-node quadratic shell element is between 7.78 and $11.67 \mathrm{~mm}$, taking into account the safety factor.

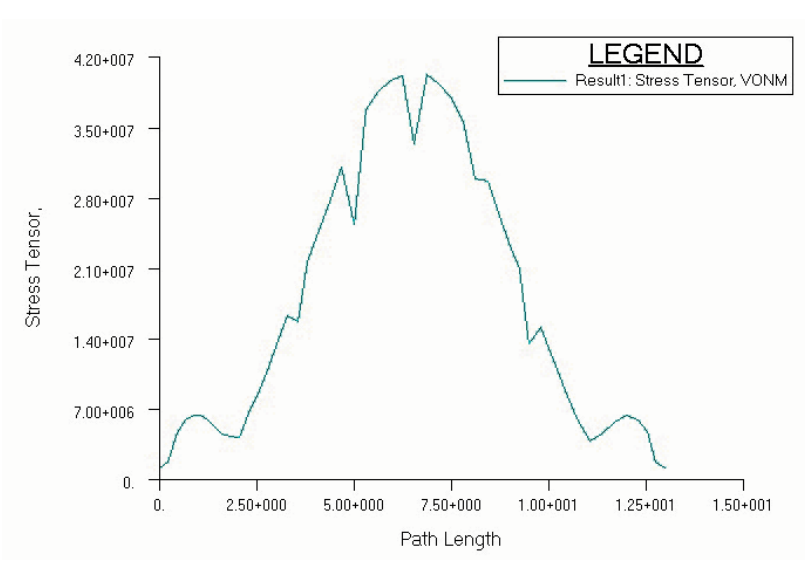

Fig. 8: Stress values of an overhead crane girder with a quadratic shell element 

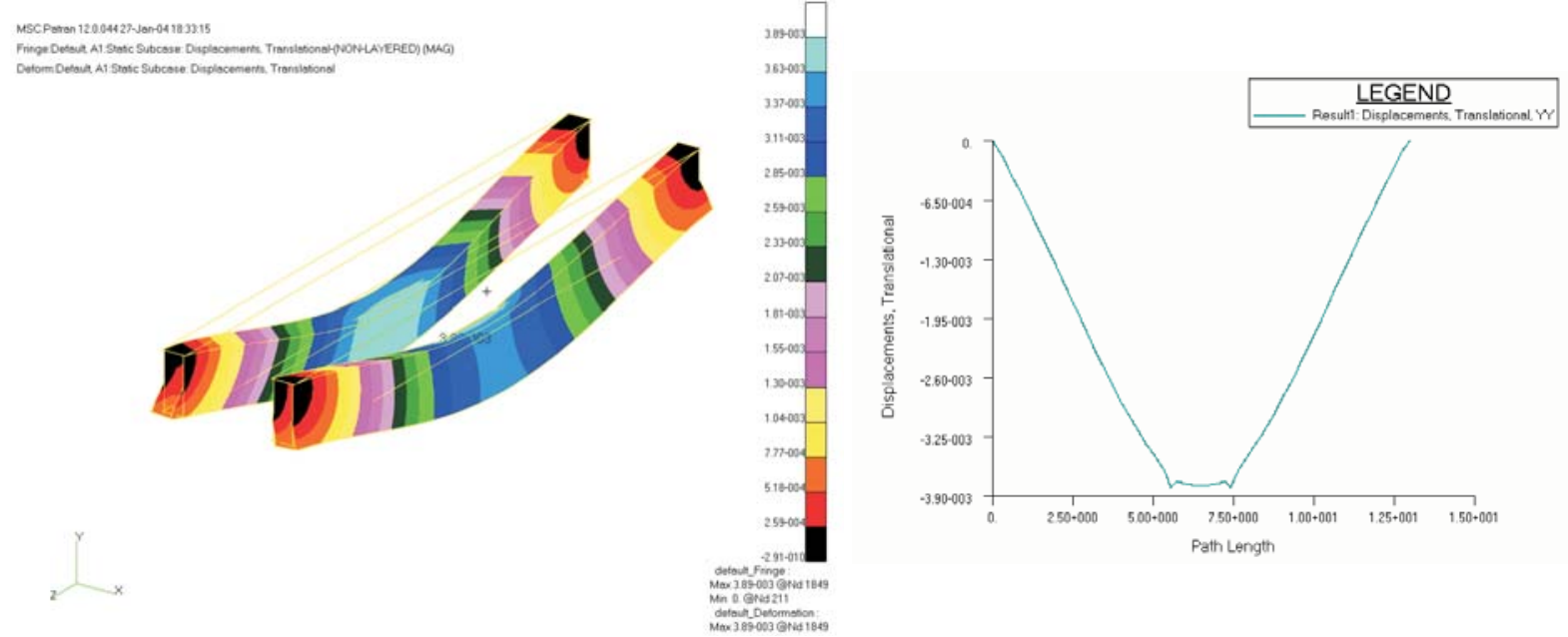

Fig. 9: Displacements of an overhead crane girder with a four-node quadratic shell element

\section{Conclusion}

In this study, unlike the other studies carried out previously, shell elements in finite element modeling of an overhead box girder have been examined. In order to show the use of shell elements, one illustrative overhead crane bridge example is given. The maximum stress value is $143.90 \mathrm{~N} / \mathrm{mm}^{2}$ and $45.24 / \mathrm{mm}^{2}$ for a four-node tetrahedral element and $147.9 \mathrm{~N} / \mathrm{mm}^{2}$ for a four-node quadratic shell element using both calculations according to the F. E. M. Rules and finite element analysis. The value of the equivalent stress is $150.18 \mathrm{~N} / \mathrm{mm}^{2}$ to two decimal places. Taking into account the safety factor, the stress value varies between $97-145.5 \mathrm{~N} / \mathrm{mm}^{2}$, which is obtained from MSC Patran.

The ratio of length to thickness of the element used in modelling the overhead crane box girder is higher than 20 . Therefore, in order to show the accuracy of the analysis of the overhead crane bridges, a four-node quadratic shell element is used instead of the four-node tetrahedral element for finite element analysis.

\section{Acknowledgment}

It is pleasure to acknowledge much stimulating correspondence with Dr. Haydar Livatyali and gratefully to acknowledge the support of CESAN Inc., which provided the design data.

\section{References}

[1] Oguamanam, D. C. D., Hansen, J. S., Heppler, G. R.: "Dynamic Responce of an Overhead Crane System." Journal of Sound and Vibration, Vol. 213 (1998), No. 5 , p. 889-906.

[2] Otani, A., Nagashima, K., Suzuki, J.: "Vertical Seismic Response of Overhead Crane." Nuclear Eng. And Design, Vol. 212 (1996), p. 211-220.

[3] Erden, A.: "Computer Automated Access to the 'F.E.M. Rules' for Crane Design.” Anadolu University Journal of Science and Technology, Vol. 3 (2002), No. 1, p. 115-130.

[4] Anon, A: "New Thinking in Mobile Crane Design." Cargo Systems, Vol. 5 (1998), No. 6, p. 81.
[5] Baker, J.: "Cranes in Need of Change." Engineering, Vol. 211 (1971), No. 3, p. 298.

[6] Buffington, K. E.: "Application and Maintenance of Radio Controlled Overhead Travelling Cranes." Iron and Steel Engineer, Vol. 62 (1985), No. 12, p. 36.

[7] Demokritov, V. N.: "Selection of Optimal System Criteria for Crane Girders." Russian Engineering Journal, Vol. 54 (1974), No. 4, p. 7.

[8] Erofeev, M. J.: "Expert Systems Applied to Mechanical Engineering Design Experience with Bearing Selection and Application Program." Computer Aided Design, Vol. 55 (1987), No. 6, p. 31.

[9] Lemeur, M., Ritcher, C., Hesser, L.: "Newest Methods Applied to Crane Wheel Calculations in Europe." Iron and Steel Engineer, Vol. 51 (1977), No. 9, p. 66.

[10] McCaffery, F. P.: "Designing Overhead Cranes for Nonflat Runways." Iron and Steel Engineer, Vol. 62 (1985), No. 12, p. 32.

[11] Reemsyder, H. S., Demo, D. A.: "Fatigue Cracking in Welded Crane Runway Girders, Causes and Repair Procedures." Iron and Steel Engineer, Vol. 55 (1978), No. 4, p. 52.

[12] Rowswell, J. C., Packer, J. A.: "Crane Girder Tie-Back Connections." Iron and Steel Engineer, Vol. 66 (1989), No. 1, p. 58.

[13] Moustafa, K. A., Abou-El-yazid, T. G.: Load Sway Control of Overhead Cranes with Load Hoisting via Stability Analysis." JSME Int. Journal, Series C, Vol. 39 (1996), No. 1, p. 34-40.

[14] Oguamanam, D. C. D., Hansen, J. S., Heppler, G. R.: "Dynamic of a Three-Dimensional Overhead Crane System." Journal of Sound and Vibration, Vol. 242 (2001), No. 3, p. 411-426.

[15] Auering, J. W., Troger, H.: "Time Optimal Control of Overhead Cranes with Hoisting of the Load." Automatica, Vol. 23 (1987), No. 4, p. 437-447.

[16] Huilgol, R. R., Christie, J. R., Panizza, M. P.: "The Motion of a Mass Hanging from an Overhead Crane." Chaos, Solutions \& Fractals, Vol. 5 (1995), No. 9, p. 1619-1631. 
[17] Demirsoy, M.: "Examination of the Motion Resistance of Bridge Cranes.” PhD. Thesis, Dokuz Eylul University, Izmir, Turkey, 1994.

[18] Ketill, P., Willberg, N. E.: "Application of 3D Solid Modeling and Simulation Programs to a Bridge Structure." PhD. Thesis, Chalmers University of Technology, Sweden.

[19] Celiktas, M.: "Calculation of Rotation Angles at the Wheels Produced by Deflection Using Finite Element Method and the Determination of Motion Resistance in Bridge Cranes." J. of Mechanical Design, Vol. 120 (1998).

[20] Alkin, C.: "Solid Modeling of Overhead Crane Bridges and Analysis with Finite Element Method.” M.Sc. Thesis, Istanbul Technical University, Istanbul, Turkey, 2004. (in Turkish)

[21] Scheffer, M., Feyrer, K., Matthias, K.: Fördermaschinen Hebezüge, Aufzüge, Flurförderzüge. Wiesbaden: Viehweg \& Sohn, 1998.
[22] Kogan, J.: Crane Design : Theory and Calculations of Reliability, New York: John Wiley \& Sons, 1976.

[23] Errichello, R.: "Gear Bending Stress Analysis." ASME Journal of Mechanical Design, Vol. 105 (1983), p. 283-284.

[24] Moaveni, S.: Finite Element Analysis : Theory and Application with ANSYS. New Jersey: Prentice-Hall, 1999.

[25] Verschoof, J.: Cranes Design, Practice and Maintenance, London: Professional Engineering Pub., 2000.

\section{Coskun Alkin}

Dr. C. Erdem Imrak

e-mail:imrak@itu.edu.tr

Dr. Hikmet Kocabas

Istanbul Technical University

Faculty of Mechanical Engineering

34439 Istanbul, Turkey 